\title{
Arranjos de Desenvolvimento da Educação (ADEs): nova oportunidade de negócios educacionais para as organizações do setor privado
}

\author{
Education Development Arrangements (ADEs): new educational business \\ opportunity for private sector organizations
} Arreglos de Desarrollo de la Educación (ADEs): nueva oportunidad de negocios educativos para las organizaciones del sector privado

ELMA JÚLIA GONÇALVES DE CARVALHO

Resumo: $\mathrm{O}$ artigo apresenta reflexões sobre os Arranjos de Desenvolvimento da Educação (ADEs), tendo como foco o ADE-Granfpolis em parceria com o Instituto Positivo. As análises, provenientes de pesquisa bibliográfica e documental, revelam que os mesmos expressam novas formas de cooperação intergovernamental, bem como da institucionalização de uma nova modalidade de parceria público-privada. Os resultados indicam que os ADEs se configuram como nova oportunidade de negócios educacionais para as organizações do setor privado.

Palavras-chave: Arranjos de Desenvolvimento da Educação (ADEs); parceria público-privada; negócios educacionais.v

Abstract: The article presents reflections on the Education Development Arrangements (ADEs), focusing on ADE-Granfpolis in partnership with Instituto Positivo. The analyzes, from bibliographical and documentary research, reveal that they express new forms of intergovernmental cooperation, as well as the institutionalization of a new modality of public-private partnership. The results indicate that ADEs are a new educational business opportunity for private sector organizations.

Keywords: Education Development Arrangements (ADEs); public-private partnership; educational businesses.

Resumen: El artículo presenta reflexiones sobre los Arreglos de Desarrollo de la Educación (ADEs), teniendo como foco el ADE-Granfpolis en asociación con el Instituto Positivo. Los análisis, provenientes de investigación bibliográfica y documental, revelan que los mismos expresan nuevas formas de cooperación intergubernamental, así como de la institucionalización de una nueva modalidad de asociación público-privada. Los resultados indican que los ADE se configuran como una nueva oportunidad de negocios educativos para las organizaciones del sector privado.

Palabras clave: Arreglos de Desarrollo de la Educación (ADEs); asociación público-privada; negocios educativos. 


\section{INTRODUÇÃO}

A partir de 1990, com a reforma do Estado, observamos que novas relações entre os setores público e privado passaram a ser priorizadas na legislação brasileira (ADRIÃO; PERONI, 2005; PERONI, 2015; ADRIÃO, 2017). Concebendo algumas atividades como não exclusivas do Estado, autorizam-se formas variadas de parcerias no âmbito da União, dos estados, do Distrito Federal e dos municípios e se admite a destinação de recursos públicos para a esfera privada.

Nocampo educacional, como em todo ocampo social, podemosidentificar, desde então, diferentes iniciativas de parcerias e relações intergovernamentais entre os entes federados ou entre entes federados e entidades com ou sem fins de lucro, dentre as quais fundos, convênios, consórcios e, mais recentemente, os denominados 'Arranjos de Desenvolvimento da Educação' (ADEs).

Neste artigo, centramos a análise nos ADEs. Elaborados na perspectiva gerencial da administração pública, tais arranjos expressam a adoção de novas formas de coordenação e de cooperação intergovernamental, bem como da institucionalização de uma nova modalidade de parceria público-privada. No caso, a parceria entre institutos e fundações ligados a empresas privadas e a organizações diversas é adotada com a justificativa da melhoria da 'qualidade social’ da Educação Básica brasileira.

Consideramos que tal parceria, mais do que um instrumento de soluções colaborativas que transpõem a administração pública, configura-se como uma nova estratégia de expansão e de controle do mercado educacional por parte do setor privado (CARVALHO, 2018) e é dessa perspectiva que focalizamos o Arranjo da Associação de Municípios da Grande Florianópolis (Granfpolis) em parceria com o Instituto Positivo. Para procedermos à análise, abordamos, inicialmente, a redefinição da relação entre o público e o privado no contexto da reforma do Estado brasileiro; em seguida, a nova configuração das relações entre o público e o privado, das novas ações filantrópicas - que alinham investimentos sociais e negócios - e das novas modalidades de parcerias no desenvolvimento da educação básica pública brasileira; por fim, explicitamos que, no processo de redefinição das fronteiras entre público e privado, os ADEs se revelam como nova oportunidade de negócios educacionais para as organizações do setor privado e de mercantilização dos serviços educacionais. 


\section{O ESTATAL, O PÚBLICO E O PRIVADO NO CONTEXTO DA REFORMA DO ESTADO BRASILEIRO}

Analisando a maneira como o Estado brasileiro vem organizando-se para o cumprimento do dever de garantir a Educação Básica, cabe-nos explicitar que, a partir dos anos de 1990, foram redimensionadas as fronteiras entre o público e o privado-mercantil, abrindo-se espaços para a crescente atuação empresarial.

Com base nas análises de Sguissardi (2015) e Peroni (2018), consideramos que, no capitalismo, o estatal não é um polo oposto ao privado, mas um campo de disputas entre interesses públicos versus interesses privados-mercantis. No contexto atual, esse campo é homogeneizado por esses últimos, razão pela qual o processo de reforma do Estado, caracterizado por orientações neoliberais e gerencialistas, tende a privilegiar a "[...] dinamização das virtualidades do sistema de mercado [...] e os processos que visam à acumulação do capital”" (SGUISSARDI, 2015, p. 876). Portanto, é no âmbito desse Estado, em que os interesses privados-mercantis se sobrepõem aos interesses públicos, que precisam ser situadas as políticas de universalização da Educação Básica e sua pretendida melhoria da qualidade.

Vivenciamos uma época marcada pela restruturação produtiva e pela mundialização do capital com predominância financeira. Em correspondência, o Estado assumiu um novo papel e uma nova forma de atuação, apoiado na adoção de políticas neoliberais

A reconfiguração do papel estatal recolocou em discussão a relação entre o público e o privado, no sentido da redefinição das fronteiras e da maior integração entre ambos. O questionamento da centralidade do Estado e da noção de público a ele circunscrito dá origem a propostas de democratização das instituições políticas, envolvendo a redefinição das fronteiras entre o público e o privado, a ampliação do público para além do estatal e o revigoramento da sociedade civil com a finalidade de recomposição do espaço público.

A noção de público não estatal contribui não apenas "Para assinalar a importância da sociedade como fonte de poder político", mas também para atribuir "À sociedade uma responsabilidade na satisfação das necessidades coletivas” (BRESSER PEREIRA; GRAU, 1999, p. 30). Assim, integrando a tomada de decisão do Estado ao movimento de extensão do capital para novas esferas econômicas ou sociais, em nome de uma suposta ampliação da esfera pública, estimula-se o fortalecimento da esfera pública não estatal e o crescente deslocamento das responsabilidades públicas com os direitos sociais para a iniciativa privada e para organizações sociais do 'terceiro setor' (ADRIÃO; PERONI, 2005; CARVALHO, 2017). 
Estamos, portanto, presenciando o surgimento de uma esfera pública que não integra o aparelho estatal e de uma esfera privada com 'sentido público'; em síntese, vivenciamos uma ruptura dos limites entre público e privado. A redefinição das fronteiras tradicionais entre o público e o privado dá margem a políticas com aparências modernizadoras, democráticas e de interesse social, mas que, em última instância, favorecem os objetivos da iniciativa privada/mercantil, já que criam novas oportunidades de negócios e de lucro.

Com base em informações básicas sobre os municípios brasileiros, obtidas por meio de pesquisas realizadas pelo Instituto Brasileiro de Geografia e Estatística (IBGE, 2012; 2016), é possível dimensionar a participação do setor privado nas seguintes áreas: educação ${ }^{1}$, saúde, assistência e desenvolvimento social, emprego e/ou trabalho, turismo, cultura, habitação, meio ambiente, transporte, desenvolvimento urbano e saneamento básico. As pesquisas abrangeram formas de associação, como os consórcios públicos e administrativos entre os diferentes entes federativos, os convênios de parceria com o setor privado e o apoio do setor privado ou de comunidades. Os dados coletados em 2011 demostram que "os convênios com participação do setor privado estavam presentes em 42,7\% e com apoio do setor privado ou de comunidades, em 26,8\% dos [municípios] que declararam formar alguma articulação interinstitucional” (IBGE, 2012, p. 40).

Importa ressaltar, além dos limites ambíguos entre ambos, um duplo movimento no processo de reconfiguração da relação entre o público e o privado. No primeiro, estão as novas formas de solidariedade baseadas na cooperação voluntária e na filantropia empresarial, nas quais os grupos de interesses se autorresponsabilizam pela solução das questões sociais, disseminando as soluções privadas e o empreendedorismo social. O segundo é o do crescente protagonismo empresarial nos encaminhamentos da questão social e o incentivo público para que a sociedade civil vinculada ao mercado interfira, elabore, dissemine e execute políticas sociais (PERONI, 2013; BALL, 2014).

Nesse processo, em nome da responsabilização e da auto-organização social, surgem novos "atores", novos papéis, novos espaços e novas relações políticas, envolvendo novos movimentos sociais e os empresários. Considerando os novos métodos empresariais e as iniciativas de empreendedorismo social, Ball e Olmedo (2013, p. 33) chamam-nos a atenção para uma 'nova filantropia' (ou "filantropia 3.0"), marcada pelo "Envolvimento direto dos doadores nas ações filantrópicas e nas comunidades de políticas", na qual se explora a compatibilidade entre lucro e filantropia e se expandem as oportunidades de negócios e o alcance das forças de mercado. 
Ball e Olmedo (2013, p. 40) destacam, ainda, que a filantropia 3.0, que faz parte de "uma nova configuração e lógica de ações de ajuda", cria novos espaços, novas motivações, novas ações e novas dinâmicas que tendem a expandir-se além do âmbito local, regional ou nacional, em correspondência com a nova tecnologia política das redes globais de influência - denominada 'filantropia de rede'.

Assim, as empresas estão evolvidas com as políticas de diferentes maneiras, incluindo novas formas de filantropia e agenciamentos globais (BALL, 2014). Merece destaque a expansão das redes de políticas públicas, suas formas de atuação, seu poder e influência sobre os governos. Outra consideração importante nas novas relações entre público e privado refere-se à abertura para as diversas modalidades de parcerias, dentre as quais a cooperação técnica, as assessorias e as consultorias de empresas para os governos, o que influencia as agendas e a tomada de decisões, bem como a gestão pública, por meio de relatórios, de recomendações e de diagnósticos alinhados à possibilidade lucrativa.

Os dados da pesquisa de informações básicas sobre os municípios brasileiros (IBGE, 2016, p. 28) demonstram que a "Contratação de empresas que fornecem mão de obra especializada para o desempenho de determinadas atividades do processo produtivo vem sendo cada vez mais frequente no setor público de uma forma geral, razão pela qual a terceirização de serviços pelas prefeituras municipais". Ainda de acordo com a pesquisa, "a assessoria era contratada em 85,8\% (4.777) dos municípios brasileiros, podendo apresentarse de diferentes formas: jurídica [como emissão de pareceres, aprovação de minutas de editais, contratos, acordos, convênios e outras ações que requeiram a ação de profissionais de Direito], contábil/ financeira [como diagnóstico, acompanhamento e avaliação da gestão orçamentária municipal], cartográfica, para realizar atividades de contratação e pagamento de funcionários, e para elaboração de projetos para captação de recursos".

Dados como esses demonstram que as diversas modalidades de parcerias têm influenciado as agendas, a tomada de decisões e a gestão pública, ao mesmo tempo em que se alinham às novas possibilidades de realização lucrativa, suscitando o crescente envolvimento empresarial na Educação Básica pública brasileira.

\section{AS NOVAS RELAÇÕES ENTRE O PÚBLICO E O PRIVADO E O CRESCENTE ENVOLVIMENTO EMPRESARIAL NA EDUCAÇÃO PÚBLICA BRASILEIRA}

Ao redefinir seu papel com base no modelo gerencial, o Estado separa as funções de planejamento e de execução de serviços. Ao abandonar o papel de executor diante da necessidade estrutural de expansão do capital, o Estado se 
exime da incumbência de fornecer serviços de forma direta e, consequentemente, transfere para a sociedade civil e para as instituições do setor privado e do público não estatal funções e serviços que, até então, eram de sua exclusiva competência. Ao mesmo tempo, vêm sendo configuradas novas estratégias de redefinição do relacionamento entre Estado e empresas privadas para fins de prestação de serviços públicos. Verificamos que a participação de novos 'atores', particularmente de empresários, está sendo reconhecida como fundamental para o alcance de melhores resultados por parte das escolas.

O envolvimento e a participação da sociedade e da comunidade empresarial nas questões educacionais são uma tendência mundial (PERONI, 2013; BALL, 2014). No Brasil, essa tendência se manifesta na atuação de empresas privadas em fundações, institutos e ONGs, cujo papel abrange a coordenação (monitoramento/controle de metas e de resultados) e a execução de ações. O movimento empresarial Todos Pela Educação, o Grupo de Institutos, Fundações e Empresas (Gife), o Instituto Ethos de Empresas e Responsabilidade Social e o Movimento Colabora Educação inserem-se nessa política que estimula a iniciativa privada e as organizações sociais do chamado 'terceiro setor' a se tornar parceiras do Estado no provimento de políticas públicas.

Nesse contexto de aproximação de interesses com o poder público, em nome de uma maior responsabilidade social, o setor privado empresarial vem intervindo sistematicamente e assumindo um papel decisivo nas questões educacionais. Ao mesmo tempo, o investimento social privado está na pauta do debate fomentado pelas empresas e pelas ONGs, sendo associado a uma forma de adicionar valor social aos negócios. Em 2016, o 'Alinhamento entre investimento social e negócio’ foi tema de publicação do GIFE. Entre outras publicações relacionadas, estão: 'Guia de tendências e práticas do investimento social empresarial' (GIFE, 2017), 'Olhares sobre a atuação do investimento social privado no campo de negócios de impacto' (GIFE, 2018) e 'Perfil das organizações da sociedade civil no Brasil' (GIFE, 2018)².

Em dezembro de 2017, o GIFE lançou a oitava edição do Censo de 2016, resultante de uma pesquisa sobre investimento social privado. Realizada desde 2001, a pesquisa teve como objetivo compreender o montante de investimento, como se investe no Brasil e quais são as empresas, as fundações e os institutos de origem empresarial, familiar, independente e comunitária que investem recursos privados em ações de finalidade pública. 
Em relação à fonte dos recursos, a pesquisa revela que o total do investimento social privado no país em 2016 foi de $\mathrm{R} \$ 2.9$ bilhões ${ }^{3}$. Um dos dados que mais chama a atenção é a área prioritária de investimento social: $84 \%$ das organizações informam que investem na área da educação, $65 \%$ na de assistência social, $61 \%$ na de saúde e $51 \%$ na de cultura e artes (GIFE, 2017, p. 3).

Essa prioridade revela que há uma associação entre oportunidade de negócios e retorno de investimentos. Segundo Voltolini, a empresa, ao realizar o seu investimento social, "seleciona temas que, de alguma forma, contribuem para melhorar a competitividade do seu empreendimento"4.

Outro dado relevante da pesquisa refere-se aos investimentos via incentivos fiscais. Embora a pesquisa mostre que essa forma de investimento "Diminuiu em 33\%, passando de R \$ 599 milhões em 2014 para R 402 milhões em 2016", e que a "Participação dos recursos incentivados no volume total do investimento caiu de $17 \%$ para 14\%", observamos que " $43 \%$ dos institutos e das fundações empresariais investem via incentivos fiscais" ".

Também chama a atenção o fato de que "Os diversos atores com os quais os investidores se relacionam estão inseridos nos processos e instâncias de tomada de decisão"'. Para Ball (2014, p. 122), o envolvimento direto dos 'novos' em ações de filantropia e de comunidades políticas explica-se porque eles esperam um 'retorno' em sua 'doação', ou seja [... ] Os 'novos' filantropos querem ver impactos e resultados claros e mensuráveis de seus 'investimentos' de tempo e dinheiro".

O Censo GIFE, ao mapear as parcerias, identificou que, além de ser uma prática comum entre os investidores sociais privados, há uma porcentagem elevada de parcerias com órgãos da administração pública direta, correspondendo a $71 \%$.

No campo da Educação Básica, visando à expansão e ao aprimoramento dos serviços educacionais, as parcerias têm sido regulamentadas e legitimadas por diferentes normativas, proporcionando condições para a atuação crescente das organizações não governamentais e das empresas privadas na rede pública de ensino. Dentre as medidas recentes, podemos citar a Resolução no 01/2012 (BRASIL,

3 Disponível em: <https://gife.org.br/gife-lanca-key-facts-com-os-principais-resultados-docenso/>. Acesso em: 14 jun. 2018.

4 Disponível em: <http://www.parceirosvoluntarios.org.br/o-valor-estrategico-do-investimentosocial-privado/>. Acesso em: 14 jun. 2018.

5 Disponível em: < https://gife.org.br/censo-2016-keyfacts/assets/pdf/censogife2016_keyfacts. pdf $>$ Acesso em: 14 jun. 2018.

6 Disponível em: <https://gife.org.br/lancamento-censo-gife-2016/>. Acesso em: 14 jun. 2018.

7 Disponível em: <https://gife.org.br/lancamento-censo-gife-2016/>. Acesso em: 14 jun. 2018. 
2012), que regulamentou os ADEs. A proposta, elaborada pelo movimento empresarial Todos Pela Educação (TPE), apresenta-se como um instrumento de gestão pública com vistas à implementação do regime de colaboração entre os entes federados, com ênfase na colaboração horizontal entre os municípios e na construção de um sistema nacional de educação (ARAÚJO, 2012). Esse regime de colaboração é considerado de um novo tipo (ARGOLLO; MOTTA, 2015), pois é aberto para que os municípios possam atuar coletivamente, em parceria e em colaboração com os estados, com o Ministério da Educação (MEC) e com os institutos e as fundações ligadas a empresas privadas (CARVALHO, 2018).

A proposta dos ADEs, elaborada com base na perspectiva gerencial da administração pública, insere-se na busca por novas formas de coordenação e cooperação intergovernamental, bem como de institucionalização de novas parcerias público-privadas para a oferta da melhoria da qualidade social da educação básica, o que implica a transposição dos limites da administração pública.

Portanto, em decorrência das mudanças significativas nas relações entre público e privado, a formulação e a execução de políticas, a partir da década de 1990, correspondem às novas fórmulas e aos novos arranjos institucionais em que o Estado não é o único protagonista. Nesse contexto, os empresários, na condição de 'novos' filantropos, têm influenciado os governos, particularmente no campo da educação, e o Estado, por sua vez, está cada vez mais envolvido em assegurar as parcerias e a criação de novos mercados ou "novas oportunidades de negócios nos serviços públicos" (BALL, 2014, p. 193), a fim de ampliar as possibilidades de acumulação do capital, conforme abordamos a seguir.

\section{ARRANJOS DE DESENVOLVIMENTO DA EDUCAÇÃO (ADES): NOVAS OPORTUNIDADES DE NEGÓCIOS}

Em 2015, o Instituto Positivo, caracterizado como uma Organização da Sociedade Civil de Interesse Público (Oscip), atuando como gestor do Investimento Social do Grupo Positivo ${ }^{8}$, definiu como prioridade o programa ADEs. Em 2017, "além de manter o apoio à implantação de ADEs", o Instituto Positivo passou a "produzir e disseminar pesquisas e informações, a fim de que

8 O Grupo Positivo é uma holding brasileira que atua nos ramos de educação privada (escolas, universidades e cursos pré-vestibular), gráfico-editorial e de informática. Segundo informações obtidas em seus sites, o Grupo Positivo lidera o ranking das maiores empresas do setor de Educação; seus clientes são aprendizes, governos e organizações públicas e privadas. 
mais municípios brasileiros possam ter informações sobre como se organizar em Regime de Colaboração, potencializando as ações cooperativas em prol do aumento da qualidade da Educação"”.

Por meio desse programa, o Instituto assumiu “o compromisso de apoiar as secretarias municipais de educação a implantar um modelo estratégico de cooperação". A escolha do regime de colaboração como uma estratégia de atuação é justificada da seguinte forma:

Atualmente, os municípios são responsáveis pelo atendimento de grande parte dos alunos brasileiros, pois aproximadamente $70 \%$ das matrículas da Educação Básica da rede pública estão vinculadas ao ensino infantil e ao fundamental. Sendo assim, boa parte do sucesso da agenda educacional do país e do alcance das metas do Plano Nacional de Educação passará pela capacidade que os municípios tiverem na condução dos seus planos locais.

A gestão de uma rede de ensino envolve uma complexidade de atividades em múltiplas dimensões, como infraestrutura, gestão, formação, remuneração e carreira docente, currículo, didáticas, legislação e até mesmo uma cultura pedagógica. Nesse sentido, o apoio mútuo gerado entre Secretarias de Educação de municípios de um mesmo território geográfico tem muito a contribuir [...] E é para suprir tais dúvidas e para estimular que mais territórios se organizem em Regime de Colaboração que o Instituo Positivo atua ${ }^{10}$.

O Programa ADE, em parceria do Instituto Positivo com a Associação de Municípios - Granfpolis ${ }^{11}$, foi lançado oficialmente em novembro de 2015 e atende 22 municípios de Santa Catarina ${ }^{12}$.

A gestão dos ADEs é orientada para uma atuação em "rede e direcionada a resultados, criando, de um lado, mecanismos para articular projetos conjuntos e, de outro, para administrar conforme metas e indicadores previamente definidos" (ABRUCIO, 2012, p. 24). Assim, com base no diagnóstico educacional e situacional do território e na identificação dos principais pontos de atenção, "O modelo estimula a construção e o monitoramento de um plano de ação conjunto entre os municípios, voltado à troca de experiências e melhoria da educação" no referido território ${ }^{13}$.

9 Disponível em: http://instituto.positivo.com.br/ Acesso em: 03 mar. 2019.

10 Disponível em: <http://instituto.positivo.com.br/> Acesso em: 15 jul. 2018.

11 A Associação dos Municípios da Região da Grande Florianópolis (GRANFPOLIS) foi fundada em 1969 com o objetivo de promover o desenvolvimento integrado da Região.

12 Os municípios participantes são Águas Mornas, Alfredo Wagner, Angelina, Anitápolis, Antônio Carlos, Biguaçu, Canelinha, Florianópolis, Garopaba, Governador Celso Ramos, Leoberto Leal, Major Gercino, Nova Trento, Palhoça, Paulo Lopes, Rancho Queimado, Santo Amaro da Imperatriz, São Bonifácio, São João Batista, São José, São Pedro de Alcântara e Tijucas.

13 Informações disponíveis em: <http://www.institutopositivo.org.br/pt/investimento/regime-decolaboracao/1>. Acesso em: 15 jul. 2018. 
Essa metodologia produziu uma nova governança na qual o Instituto Positivo atua junto à Granfpolis e às lideranças do ADE como o "facilitador e o mentor técnico", ou seja, "na formulação e no apoio a operacionalização das metas" (ABRUCIO, 2017, p. 150). O ADE conta com a liderança do Assessor de Assuntos Educacionais da Associação Granfpolis, além de três líderes representados por Secretários de Educação, os quais têm o papel de "articular as iniciativas, apoiar o Arranjo, viabilizar metas e aproximar parceiros". Para Abrucio (2017, p. 156): "Essa característica da governança, ademais, auxiliou na permanência das metas ${ }^{14}$ e das ações planejadas mesmo com a mudança de $72 \%$ dos prefeitos que assumiram o mandato em 2017, já que as equipes técnicas permaneceram e deram continuidade ao movimento".

A análise e a interpretação dos dados autorizam a hipótese de que, além de se configurar como um novo instrumento de soluções colaborativas das organizações educacionais que atuam em território comum, tais arranjos, embora aparentemente não envolvam a transferência de recursos para as instituições privadas e não governamentais (BRASIL, 2012), podem revelar-se como novas oportunidades de negócios para as organizações do setor empresarial.

Para desenvolver essa hipótese, necessitamos expor alguns dados, especialmente os que se referem à aquisição de soluções educacionais e aos contratos celebrados entre os municípios envolvidos no ADE/Granfpolis com a Editora Positivo. Em levantamentos realizados em diários oficiais dos municípios de Santa Catarina e em portais da transparência, observamos que os municípios têm adquirido o Sistema de Ensino Aprende Brasil ${ }^{15}$, que oferece um conjunto específico de soluções para a rede de ensino municipal pública.

Conforme atestado na Ata de Registro de Preços n. ${ }^{\circ}$ 11/2016, divulgada no Diário Oficial de dos Municípios de Santa Catarina (DOM/SC), em 2016, houve a aquisição, por um ano, de um composto educacional para a educação infantil e o ensino fundamental pela rede pública de ensino do município de Governador Celso Ramos.

14 As metas definidas são: "Meta 1: melhoria do aprendizado; Meta 2: correção de fluxo escolar; Meta 3: implementação de 1/3 da hora atividade; Meta 4: avaliação institucional” (ABRUCIO, 2017, p. 189).

15 Segundo matéria divulgada em dezembro de 2017, "Atualmente, o Sistema de Ensino Aprende Brasil está presente em mais de 2 mil escolas públicas, em cerca de 220 municípios brasileiros". Disponível em: <http://www.laranjeirasdosul.pr.gov.br/mobile/exibe_noticia.php?id=239>. Acesso em: 16 jul. 2018. 
O respectivo composto pedagógico deverá disponibilizar material didático pedagógico, uma mídia digital com conteúdos educacionais, um serviço de formação continuada aos professores e equipe técnica, um sistema de avaliação do desempenho acadêmico dos alunos do $4^{\circ}$ e $8^{\circ}$ ano do ensino fundamental e ainda, um sistema de diagnóstico de fatores institucionais que compõem a educação municipal que possa avaliar os avanços educacionais do referido município durante a vigência do contrato (DOM/SC, 2016, p. 461).

A tabela contida na Ata de Registro de Preços n. ${ }^{\circ}$ 11/2016 informa os seguintes valores por aluno:

\section{Imagem 1: Tabela do Edital}

\begin{tabular}{|c|c|c|c|c|c|}
\hline \multicolumn{7}{|c|}{ LOTE ÚNICO - TABELA CONTIDA NO ANEXO I DO EDITAL } \\
VALORE S POR ALUNOS
\end{tabular}

\begin{tabular}{|l|l|l|l|l|l|}
\hline 09 & $4^{\circ}$ gno & 320 & 97,92 & 391,68 & $125.337,60$ \\
\hline 10 & $5^{\circ}$ gno & 310 & 97,92 & 391,68 & $121.420,80$ \\
\hline 11 & $6^{\circ}$ ano & 250 & 100,97 & 403,88 & $100.970,00$ \\
\hline 12 & $7^{\circ}$ gno & 310 & 100,97 & 403,88 & $125.202,80$ \\
\hline 13 & $8^{\circ}$ gno & 230 & 100,97 & 403,88 & $92.892,40$ \\
\hline 14 & $9^{\circ}$ gno & 200 & 100,97 & 403,88 & $80.776,00$ \\
\hline
\end{tabular}

Fonte: Ata de Registro de Preços no 11/2016, PMGCR, p. 1-2 (DOM/SC, 2016, p. 461).

Verifica-se que, na Educação Infantil, a estimativa foi atender 1.270 alunos por ano, com um investimento de $\mathrm{R} \$ 433.667,00$, e, no Ensino Fundamental, foi atender 2.660 alunos por ano, com um investimento de $\mathrm{R} \$ 1.053 .946,80$. Portanto, no total, foram 3.930 alunos e $\mathrm{R} \$ 1.487 .612380$ (DOM/SC, 2016, p. 461). 
Por meio do $2^{0}$ Termo Aditivo ${ }^{16}$ ao contrato de prestação de serviços 19/2017 com a Empresa Editora Positivo, referente à Inexigibilidade de Licitação no 31/2017, Processo 031/2017, em janeiro de 2018, o município de Governador Celso Ramos adquiriu, para "o terceiro bimestre de 2017 até o segundo bimestre de 2018", um "Composto pedagógico destinado ao uso no processo educacional dos alunos da Educação Infantil e Ensino Fundamental da rede pública de ensino" (DOM/SC, 2018b, p. 266). Nos termos do documento, o número de alunos contemplados e os valores informados são os seguintes:

2.3. Faz-se assim, necessária a adição de 38 alunos ao item 3 (76 apostilas - apostila semestral), 42 alunos ao item 4 (168 apostilas - apostila por bimestre), 27 alunos ao item 7 (108 apostilas - apostila por bimestre), 48 alunos ao item 8 (192 apostilas apostila por bimestre) e 52 alunos ao item 11 (208 apostilas - apostila por bimestre) da Cláusula $2^{\mathrm{a}}$ item 2.1 do contrato, ficando este aditivo no valor total de R\$ $80.953,60$ (oitenta mil e novecentos e cinquenta e três reais e sessenta centavos) restando dentro do limite de $25 \%$ previsto pela lei $8.666 / 93$, perfazendo o valor total do contrato em R \$1.049.779,60 (Hum milhão quarenta e nove mil setecentos e setenta e nove reais e sessenta centavos), uma vez que para a devida execução do contrato demandará o acréscimo de alunos supracitado (DOM/SC, 2018b, p. 266).

Em 2018, a Secretaria Municipal de Educação de Canelinha firmou convênio com a Editora Positivo. Segundo notícia postada pela Editora Positivo, "A partir dessa parceria, escolas mantidas pela prefeitura passam a adotar o Sistema de Ensino Aprende Brasil para 840 alunos dos $4^{\circ}$ e $5^{\circ}$ níveis da Educação Infantil e $1^{\circ}$ ao $5^{\circ}$ ano do Ensino Fundamental" ${ }^{\prime 17}$. Na notícia, a Editora esclarece que, com o convênio,

Além [...] além do material didático, a Secretaria Municipal de Educação recebe assessoria pedagógica para os professores e o apoio de uma coordenação pedagógica regional, a fim de auxiliar os gestores educacionais no processo de implementação

16 No $1^{\circ}$ Termo Aditivo ao contrato de prestação de serviços 19/2017, do qual fazem entre si o Município de Governador Celso Ramos e a Empresa Editora Positivo, referente à Inexigibilidade de Licitação n. $.^{\circ} 31 / 2017$, Processo 031/2017, data de 18 de janeiro de 2018, consta que "1.1.O presente Termo tem por objeto acrescentar 100 alunos ao item 2 da Clausula $2^{\mathrm{a}}$ item 2.1 a partir da data de 18/01/2018". Quanto aos valores, é informado que "2.3. Faz-se assim, necessária a adição de 100 alunos ao item 2 da Clausula $2^{a}$ item 2.1 no valor total de $\mathrm{R} \$ 29.500,00$ (vinte e nove mil e quinhentos reais) restando dentro do limite de $25 \%$ previsto pela lei 8.666/93, perfazendo o valor total do contrato em $\mathrm{R} \$ 968.826,00$ (novecentos e sessenta e oito mil oitocentos e vinte e seis reais), uma vez que para a devida execução do contrato demandará o acréscimo de alunos supracitado" [DOM/SC, 2018a, p. 298).

17 Disponível em: <http://www.centralpress.com.br/rede-municipal-de-ensino-de-canelinha-firmaconvenio-com-sistema-aprende-brasil/>. Acesso em: 16 jul. 2018. 
do sistema na região e atender demandas educacionais específicas da localidade. O Sistema de Ensino Aprende Brasil permite a integração dos livros com uma plataforma virtual de aprendizagem, apresentando conteúdos e atividades de todas as áreas do conhecimento. [...] Entre os diferenciais da assessoria pedagógica está o atendimento aos professores por meio de cursos presenciais e à distância, utilizando estratégias como web conferências, web atendimento e e-mails. A rede municipal também passa a contar com dois métodos auxiliares de avaliação: o Hábile (Sistema de Avaliação Positivo) e o SIMEB (Sistema de Monitoramento Educacional do Brasil) que contribuem tanto para a avaliação da gestão educacional, como para a avaliação do desempenho particularizado das turmas ${ }^{18}$.

Do site do município de Canelinha, na notícia Canelinha adota Sistema Positivo de ensino na educacãa ${ }^{19}$, publicada em 21 de dezembro de 2017, consta:

Serão contemplados com o sistema todos os alunos do Pré-escolar 1 e 2, e das séries iniciais, do $1^{\circ}$ ao $5^{\circ}$ ano do Ensino Fundamental [...] O investimento da Secretaria de Educação de Canelinha no Sistema Aprende Brasil será de R \$333.096,00.

Em licitação publicada no Diário Oficial do Estado de Santa Catarina (DOE/SC, 2017, p. 32), no 20.451, de 11 de janeiro de 2017, o município de Rancho Queimado tornou público o interesse de "contratar empresa jurídica de direito privado para a prestação de serviço a ser executada de forma contínua, para a implantação do Sistema educacional nas áreas da Educação Infantil e Ensino Fundamental"20.

Identificamos, por meio dos diários oficiais dos municípios do Estado de Santa Catarina (DOM/SC), que, além dos municípios que integram o ADE/ Granfpolis, inúmeros municípios da região têm adquirido materiais didáticopedagógicos, sistema de avaliação de desempenho acadêmico e acompanhamento da gestão educacional da Editora Positivo. Além disso, em 2017, foram aplicadas, nos municípios que abrangem o Arranjo, “17.900 provas Hábile” (GRANFPOLIS, 2016, p. 58), o que reforça a hipótese de que os Arranjos ampliam as possibilidades de vantagens competitivas para os produtos das empresas parceiras.

É importante mencionar que o Grupo Positivo tem buscado a diversificação de seus produtos e a expansão de seus negócios. Em 2006, a Positivo Tecnologia S.A. tornou-se uma empresa de capital aberto com ações listadas na Bolsa de Valores de São Paulo (BM\&FBOVESPA: POSI3): a finalidade era captar

18 Disponível em: <http://www.centralpress.com.br/rede-municipal-de-ensino-de-canelinha-firmaconvenio-com-sistema-aprende-brasil/>. Acesso em: 16 jul. 2018.

19 Disponível em: <http://www.canelinha.sc.gov.br/noticias/index/ver/codMapaItem/33817/ codNoticia/462837>. Acesso em: 16 jul. 2018.

20 Disponível em: <https://www.jusbrasil.com.br/diarios/134254989/doesc-11-01-2017-pg-32>. Acesso em: 16 jul. 2018. 
recursos dos investidores para financiar seus projetos de investimento e aumentar sua competitividade. Nos relatórios destinados a anunciar seus resultados financeiros e operacionais, observamos que grande parte dos lucros advêm de vendas para o mercado de governo e de vendas de tecnologias educacionais. Os resultados referentes ao $4^{\circ}$ trimestre de 2017 (4T17) e ao ano de 2017, apontam um "crescimento de 71,3\% nas vendas de PCs no mercado brasileiro no 4T17, sendo: $+18,5 \%$ no Varejo; $+344,9 \%$ no Governo; e $+64,5 \%$ no Corporativo" (POSITIVO TECNOLOGIA S.A., B3: POSI3 BM \& FBovespa 4T17, 2018, p.1).

Segundo informações fornecidas pela Companhia aos investidores, existe uma perspectiva de crescimento expressivo do mercado de software e de portais educacionais brasileiros em médio e longo prazo:

No Brasil, cerca de $90 \%$ das quase 200 mil escolas de ensino infantil, fundamental e médio são públicas e destas, apenas uma minoria tem acesso a computadores, Internet e tecnologia educacional [...] De 2000 a 2005, o percentual de escolas públicas de Ensino Fundamental com acesso à Internet passou de cerca de 3,9\% para 14,8\%, percentual ainda muito aquém do que se observa em países desenvolvidos - os EUA já proviam acesso à 98\% de suas escolas públicas no ano de 2000 [...] Considerando que a ampliação do mercado de software e portais educacionais brasileiro é função do crescimento da inclusão digital e de investimentos na melhoria da educação nas escolas públicas, diante dos acontecimentos recentes e do já expressivo tamanho da população estudantil brasileira, estima-se que o setor de tecnologia educacional deve experimentar um crescimento expressivo no médio e longo prazos ${ }^{21}$.

O sistema de ensino tornou-se o principal negócio do Grupo Positivo, que se destaca entre as grandes empresas educacionais do Brasil ao lado da Kroton Educacional, do Ser Educacional, da Somos Educação ${ }^{22}$ etc. Em 2016, o Grupo Positivo anunciou a expansão do número de escolas em todo o território nacional. Para alimentar essa forma de expansão e se tornar mais competitivo, o Grupo planeja uma oferta pública inicial (IPO) 23 da unidade de educação para 2019. Segundo Lucas Guimarães, vice-presidente do Grupo Positivo, “a companhia ainda não contratou bancos para coordenar a oferta, mas que tem visto elevado

21 Disponível em: http://ri.positivotecnologia.com.br/conteudo_pt.asp?idioma=0\&conta=28\&ti po=63799\#2 Acesso em |: 16 jun 2018.

22 Em 2018, a Kroton Educacional, maior empresa do segmento do ensino superior no Brasil, anunciou a compra do controle da Somos Educação, que atua no setor da educação básica.

23 "IPO (do inglês Initial Public Offering ou Oferta Pública Inicial) é o processo pelo qual as ações de uma empresa são vendidas ao público (pessoas físicas e pessoas jurídicas) pela primeira vez, via Bolsa de Valores (no caso Bovespa). É o processo pelo qual uma empresa torna-se uma empresa ou sociedade anônima de capital aberto" (SGUISSARDI, 2015, p. 886). 
interesse de investidores por empresas administrando escolas" 24 , a exemplo de empresas educacionais como a Kroton Educacional, o Ser Educacional, a Pearson Sistemas do Brasil S.A. Cabe mencionar que o setor educacional do mercado de ações tem se revelado um dos mais lucrativos da Bovespa nos últimos anos (SGUISSARDI, 2015).

No Relatório de Sustentabilidade do Grupo Positivo referente aos anos de 2014/2015, consta a seguinte afirmação: “Temos trabalhado para ampliar o impacto de nossas ações e de nossos investimentos e, em 2015, definimos a educação pública como nossa prioridade" (POSITIVO, 2016, p. 35). Nesse mesmo ano, ocorre a primeira experiência do Instituto Positivo com o ADE-Granfpolis, tendo como finalidade "produzir materiais de referência que visam inspirar e apoiar outros municípios a criar seus próprios arranjos" e "atuar como um agente fomentador da metodologia no Brasil” (Idem, 2016, p. 41). Na perspectiva da 'filantropia 3.0', esse tipo de atuação, além de abrir outras dimensões para o marketing da empresa, certamente contribui para a valorização de suas ações no mercado financeiro.

\section{CONSIDERAÇÕES FINAIS}

Ao tecermos considerações sobre a redefinição da relação entre o público e o privado no contexto da reforma do Estado brasileiro, , buscamos destacar que, embora o estatal não seja um polo oposto ao privado e se apresente como um campo de disputas entre os interesses das classes sociais, no contexto atual, ele se homogeneíza pelos interesses privados-mercantis (SGUISSARDI, 2015; PERONI, 2018). Assim, o Estado, por meio de novas regulamentações jurídicoinstitucionais, tem atuado na criação de condições favoráveis à abertura de novos espaços de acumulação do capital que, até então, eram considerados fora do alcance da lucratividade.

Quanto a esse aspecto, destacamos a análise de Adrião (2017) sobre as alterações na maneira como o Estado brasileiro se organiza para cumprir seu dever de garantir o direito à Educação Básica: “as estratégias que vigoram nesse começo de século, e que passam a compor programas de governos de diversos estados e municípios brasileiros" (ADRIÃO, 2017, p. 17). Para a autora, "a transferência da gestão da escola e dos sistemas de ensino público para setores privados, com ou sem fins de lucro", ou ainda pela "adoção pelas redes públicas dos sistemas privado de ensino" (Idem, p. 18), tem se constituído em estratégias que objetivam "transformar as redes públicas em um campo para seus negócios" (Idem, p. 30). 
Os estudos de Adrião (2017) são cruciais para o entendimento de que, ao permitir novas formas de relacionamento do setor público com o setor privado, o Estado desempenha importante papel na criação de novas oportunidades de negócios educacionais para as organizações do setor privado que atuam no campo educacional, alinhando investimento social e negócios, bem como para a mercantilização dos serviços educacionais, inclusive na Educação Básica.

O agravante nessa relação é o reconhecimento ou a legitimação, por diferentes normativas (CARVALHO, 2018), da participação do setor privado, com fins ou não de lucro (fundação e institutos), na expansão da oferta e na melhoria da qualidade social da educação básica pública. Cabe investigar as consequências disso para a organização e a gestão das escolas e das redes de ensino públicas.

Neste artigo procuramos contribuir para o debate, chamando a atenção, com base em dados e observações, para os novos formatos da relação entre o público e o privado no Brasil e para os novos processos de ampliação do campo dos negócios educacionais, dos quais os ADEs fazem parte.

\section{REFERÊNCIAS}

\section{LIVROS, PERIÓDICOS, TESES E DISSERTAÇÕES}

ABRUCIO, F. L. Cooperação intermunicipal: experiências de arranjos de desenvolvimento da educação. Colabora Educação; Instituto Positivo, 2017. Disponível em: <http://instituto.positivo.com.br/wp-content/ uploads/2017/11/Coopera\%C3\%A7\%C3\%A3o-Intermunicipal-livro-virtual. pdf>. Acesso em: 14 fev. 2018.

ABRUCIO, F. L. Associativismo territorial para a coordenação intergovernamental. In: ABRUCIO, F. L.; RAMOS, M. N. (Orgs.). Regime de colaboração e associativismo territorial: arranjos de desenvolvimento da Educação. São Paulo: Moderna, 2012, p. 17-30.

ADRIÃO, T. A privatização da educação básica no Brasil: considerações sobre a incidência de corporações na gestão da educação pública. In: ARAÚJO, L.; MARCELINO, J. Público x privado em tempos de golpe. São Paulo: Fundação Lauro Campos, 2017. p. 16-37. Disponível em <https://www.researchgate. net/publication/319376858_A_privatizacao_da_educacao_basica_no_Brasil_ consideracoes_sobre_a_incidencia_de_corporacoes_na_gestao_da_educacao_ publica>. Acesso em: 22 jan. 2018. 
ADRIÃO, T.; PERONI, V. M. V. Público não-estatal: estratégias para o setor educacional brasileiro. In: ADRIÃO, T.; PERONI, V. M. V. (Orgs.). O público e o privado na educação: interfaces entre Estado e sociedade. São Paulo: Xamã, 2005, p. 137-153.

ARAÚJO, G. C. de.. Federalismo cooperativo e arranjos de desenvolvimento da educação: o atalho silencioso do empresariado para a definição e regulamentação do regime de cooperação. Revista Brasileira de Política e Administração da Educação, v. 28, n. 2, p.515-531 mai/ago. 2012.

ARGOLLO, J.; MOTTA, V. Arranjos de desenvolvimento da educação: regime de colaboração de 'novo' tipo como estratégia do capital para ressignificar a educação pública como direito. Universidade e Sociedade, ANDES-SN, n. 56, p. 44-57, ago. 2015. Disponível em: < http://www.andes.org.br/imprensa/publicacoes/ imp-pub-719215657.pdf>. ?Acesso em: 14 jul. 2018.

BALL, S. J.; OLMEDO, A. A "nova" filantropoia, o capitalismo social e as redes de políticas globais em educação. In: PERONI, V. M. V. (Org.). Redefinição das fronteiras entre público e privado: implicações para a democratização da educação. Brasília, Liber Livro, 2013. p. 33-47.

BALL, S. J. Educação global S.A.: novas redes políticas e o imaginário neoliberal. Ponta Grossa: UEPG, 2014.

BRASIL. Resolução no 1, de 23 de janeiro de 2012. Dispõe sobre a implementação do regime de colaboração mediante Arranjo de Desenvolvimento da Educação (ADE) como instrumento de gestão pública para a melhoria da qualidade social da educação. Brasília, DF: MEC/CNE/CEB, 2012. Disponível em: < http://portal. mec.gov.br/index.php?option $=$ com_docman\&view $=$ download\&alias $=9816$ rceb001-12\&Itemid=30192> . Acesso em: 24 ago. 2017.

BRESSER PEREIRA, L. C.; GRAU, N. C. Entre o Estado e o mercado: o público não-estatal. In: BRESSER PEREIRA, L. C.; GRAU, N. C. (Org.). O público não-estatal na Reforma do Estado. Rio de Janeiro: Fundação Getúlio Vargas, 1999. p.15-48. 
CARVAlHO, E. J. G. Arranjos de Desenvolvimento da Educação (ADEs): instrumento de soluções colaborativas para a educação ou uma nova estratégia de expansão e de controle do mercado educacional? Currículo sem Fronteiras, v. 18, n. 1, p. 103-128, jan./abr. 2018. Disponível em: <http://www. curriculosemfronteiras.org/vol18iss1articles/carvalho.pdf $>$. Acesso em: 14 jul. 2018.

CARVALHO, E. J. G. A educação básica brasileira e as novas relações entre o Estado e os empresários. Revista Retratos da Escola, Brasília, v. 11, n. 21, p. 525-541, jul./dez. 2017.

DOM/SC. Edição $\mathbf{n}^{\circ}$ 2435, de 19/01/2018a. Extrato do Segundo Termo Aditivo ao Contrato no ${ }^{\circ}$ 19/2017 - $2^{\circ}$ Termo Aditivo ao Contrato de Prestação de Serviços 19/2017 que fazem entre si o Município de Governador Celso Ramos e a Empresa Editora Positivo, referente à Inexigibilidade de Licitação no 31/2017, Processo 031/2017. Disponível: http://edicao.dom.sc.gov.br/pdfjs/ web $/$ viewer.html?file $=$ http $\% 3 \mathrm{~A} \% 2 \mathrm{~F} \% 2$ Fedicao.dom.sc.gov.br $\% 2 \mathrm{~F} 1516377243$ edicao_2435_assinado.pdf\#page=298 Acesso em: 11 mai 2018.

DOM/SC. Edição $\mathbf{n}^{\circ}$ 24548, de 15/02/2018b. Extrato do Segundo Termo Aditivo ao Contrato no ${ }^{\circ}$ 19/2017 - $2^{\circ}$ Termo Aditivo ao Contrato de Prestação de Serviços 19/2017 que fazem entre si o Município de Governador Celso Ramos e a Empresa Editora Positivo,referente à Inexigibilidade de Licitação no 31/2017, Processo 031/2017. Disponível: < http://edicao.dom.sc.gov.br/pdfjs /

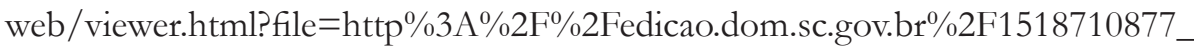
edicao_2454_assinado.pdf\#page=266>. Acesso em: 11 maio 2018.

DOM/SC - Edição n ${ }^{\circ}$ 1704, 17/03/2015. Extrato da Ata de Registro de Preços n ${ }^{\circ}$ 009/2015. Prefeitura Municipal de Governador Celso Ramos. Pregão Presencial $n^{\circ} \quad 70 / 2014<$ http://edicao.dom.sc.gov.br/1426615399_edicao_dom_1704. pdf\#nameddest=708093>. Acesso em: 11 mai 2018.

GIFE - Grupos de Institutos, Fundações e Empresas. KEY FACTS Sobre o Investimento Social no Brasil, Censo GIFE 2016. São Paulo, GIFE, 2017. Disponível em:<https://gife.org.br/censo-2016-keyfacts/assets/pdf/ censogife2016_ keyfacts.pdf>. Acesso em: 16 fev. 2018. 
GRANFPOLIS. Relatório de atividades e prestação de contas. Exercício 2016. Disponível em: < https://static.fecam.net.br/uploads/1542/arquivos/1151088_ Relatorio_2016.pdf>. Acesso em: 19 fev. 2018.

IBGE - Instituto Brasileiro de Geografia e Estatística Perfil dos Municípios Brasileiros - 2015. Rio de Janeiro, IBGE, 2016. <https://biblioteca.ibge.gov.br/ visualizacao/livros/liv95942.pdf>. Acesso em: 20 jan. 2018.

IBGE - Instituto Brasileiro de Geografia Estatística. As fundações privadas e associações sem fins lucrativos no Brasil - 2010. Estudos \& pesquisas: informação econômica, n. 20. Rio de Janeiro: IBGE, 2012. Disponível em: <ftp://ftp.ibge.gov.br/Fundacoes_Privadas_e_Associacoes/2010/fasfil.pdf>. Acesso em: 20 jan. 2018.

IBGE. Instituto Brasileiro de Geografia e Estatística. Perfil dos Municípios Brasileiros - 2011. Disponível em: <ftp://ftp.ibge.gov.br/Perfil_ Municipios/2011/munic2011.pdf>. Acesso em: 20 jan. 2018.

INSTITUTO POSITIVO; GANFPOLIS. Arranjo de desenvolvimento da educação. Revista de Resultados ADE/Granfpolis. Granfpolis; Instituto Positivo, 2017. Disponível em: <http://instituto.positivo.com.br/wp-content/ uploads/2017/12/Revista-IP-ADE-2017.pdf>. Acesso em: 18 jan. 2018.

PERONI, V. M. V.. Múltiplas formas de materialização do privado na educação básica pública no brasil: sujeitos e conteúdo da proposta. Currículo sem Fronteiras, v. 18, n. 1, p. 212-238, jan./abr. 2018.

PERONI, V. M. V. Implicações da relação público-privado para a democratização da educação no Brasil. In: PERONI, V. M. V. (Org.). Diálogos sobre as redefinições no papel do Estado e nas fronteiras entre público e privado na educação. São Leopoldo, Oikos, 2015, p .15-34.

PERONI, V. M. V.. A privatização do público: implicações para a democratização da educação. In: PERONI, V. M. V. (Org.) Redefinições das fronteiras entre o público e o privado: implicações para a democratização da educação. Brasília: Liber Livro, 2013. p. 9-32. 
POSITIVO TECNOLOGIA S.A., B3: POSI3 BM\&FBovespa 4T17. 2018. Disponível em: <http://bvmf.bmfbovespa.com.br/ cias-listadas/empresas-listadas/ResumoDemonstrativosFinanceiros. aspx?codigoCvm=20362\&idioma=pt-br>. Acesso em: 18 maio 2018.

POSITIVO. Relatório sustentabilidade de 2014/2015. 2016. Disponível em: $<$ http://positivo.com.br/ instituto/ sustentabilidade/>. Acesso em: 25 out. 2017.

SGUISSARDI, V. Educação superior no Brasil: democratização ou massificação mercantil? Educação \& Sociedade, Campinas, v. 36, n. 133, p. 867-889, out./ dez. 2015. Disponível em: <http://www.scielo.br/pdf/es/v36n133/1678-4626es-36-133-00867.pdf>. Acesso em: 14 jul. 2018.

VOLTOLINI. R. O valor estratégico do Investimento Social Privado. Parceiros Voluntários. Disponível em: <http://www.parceirosvoluntarios.org.br/o-valorestrategico-do-investimento-social-privado/>. Acesso em: 14 jun. 2018.

\section{SITES}

http://www.canelinha.sc.gov.br

http://www.centralpress.com.br

https://economia.uol.com.br

https://gife.org.br

http://www.institutopositivo.org.br

http://www.laranjeirasdosul.pr.gov.br

http://www.parceirosvoluntarios.org.br

http://www.positivo.com.br/

http:// ri.positivotecnologia.com.br

https://sinapse.gife.org.br/

ELMA JÚLIA GONÇALVES DE CARVALHO é pós-Doutoranda pelo Programa de Pós-Graduação da Universidade Federal do Rio Grande do Sul (UFRGS), sob a supervisão da Prof. ${ }^{a}$ Dr. ${ }^{a}$ Vera Maria Vidal Peroni. Docente do Departamento de Teoria e Prática da Educação e do Programa de Pós-Graduação em Educação da Universidade Estadual de Maringá. Maringá, PR-Brasil. E-mail: elamjulia@ hotmail.com 